\title{
Anticipated Difficult Airway Management with McGrath Mac Videolaryngoscope for a Case of Pyriform Fossa Carcinoma: A Case Report
}

\author{
Saloni K Shah
}

\begin{abstract}
Pyriform fossa carcinoma is usually an exophytic squamous cell carcinoma which may lead to a change in the anatomy and pathophysiology of the airway. Total laryngectomy is required in such cases. Airway management is challenging for such patients from both surgical and anesthesiologist's perspective during anesthesia induction. These patients usually present in the advanced stages affecting the surrounding structures, requiring a definite surgical intervention. Management of the difficult airway during the perioperative period is also a difficult task. We are reporting here anesthesia management of a case of right pyriform fossa carcinoma with glottic extension that was posted for total laryngectomy with partial pharyngectomy, right hemithyroidectomy, and bilateral modified radical neck dissection as the lymph nodes were involved. A difficult airway situation was anticipated as a soft tissue growth was crossing the midline covering the glottic opening, involving the aryepiglottic fold and vocal cords as shown on the CT scan.
\end{abstract}

Keywords: Anticipated difficult airway, Awake intubation, McGrath Mac videolaryngoscopy, Pyriform fossa carcinoma.

Research and Innovation in Anesthesia (2020): 10.5005/jp-journals-10049-0085

\section{INTRODUCTION}

Carcinoma of the pyriform fossa is a common hypopharyngeal cancer. ${ }^{1}$ It usually presents in patients aged 60-70 years. It occurs mainly in men and is associated with alcohol and tobacco chewing. It usually spreads anteriorly into the supraglottic and glottic larynx. Giving anesthesia to such patients is a challenging task due to the sharing of the airway between the surgeon and anesthetist. We are reporting here a case of anticipated difficult airway due to a 32 $\times 26 \mathrm{~mm}$ soft tissue growth in the right pyriform fossa with glottic extension posted for surgery in our peripheral hospital.

\section{Case Description}

A male patient of 56 years old, weighing $50 \mathrm{~kg}$, presented with hoarseness of voice, and difficulty in breathing for 2 months with a progressive increase in the intensity of the symptoms over the last 2 weeks. The patient provided written informed consent for the publication of her information and images. After histopathological and radiological investigations, the patient was diagnosed with poorly differentiated squamous cell carcinoma of the right pyriform fossa, eroding the thyroid lamina, and involving the aryepiglottic fold and the vocal cords (Fig. 1). The patient was posted for total laryngectomy, right hemithyroidectomy, and bilateral modified radical neck dissection (MRND) for the same. A pre-anesthetic check-up revealed that he was a chronic tobacco chewer for the last 20 years and had no other comorbidities. The preoperative airway examination revealed a class 3 Mallampati airway with a mouth opening of three fingers. A $2 \times 3 \mathrm{~cm}$ solid mass was seen on the right side of the neck. Indirect laryngoscopy showed an exophytic soft tissue growth in the oral cavity which was occluding more than half of the glottic opening on the right side. General and systemic examination revealed no abnormalities. All other investigations were within normal limits. We anticipated difficult intubation due
Department of Anesthesia, Bharatratna Dr Babasaheb Ambedkar Municipal Hospital, Mumbai, Maharashtra, India

Corresponding Author: Saloni K Shah, Department of Anesthesia, Bharatratna Dr Babasaheb Ambedkar Municipal Hospital, Mumbai, Maharashtra, India, Phone: +91 7666412031, e-mail: salonishah492@ gmail.com

How to cite this article: Shah SK. Anticipated Difficult Airway Management with McGrath Mac Videolaryngoscope for a Case of Pyriform Fossa Carcinoma: A Case Report. Res Inno in Anesth 2020;5(1):18-20.

Source of support: Nil

Conflict of interest: None

to the deformed anatomy of the larynx. Surgeons requested for oral intubation as an elective tracheostomy would interfere in their surgical field. In that case, awake fiberoptic intubation is the first choice but fiberoptic bronchoscope (FOB) was not available in our peripheral hospital. Hence, we planned for awake oral intubation with the help of McGrath ${ }^{\circledast}$ Mac videolaryngoscope (VL). ${ }^{2,3}$ In case of emergency, surgeons were asked for tracheostomy standby.

The patient was kept nil by mouth for 8 hours. He was counseled for awake oral intubation and was informed about the surgical procedure. Written informed consent was obtained from the relative and the patient. The airway was prepared with $2 \mathrm{~mL}$ of $4 \%$ lignocaine nebulization for topical anesthesia and intramuscular glycopyrrolate $0.2 \mathrm{mg}$ was given as antisialagogue in the preoperative area. ${ }^{4}$ An intravenous (IV) line was secured with $18 \mathrm{G}$ IV cannula. Baseline heart rate-68 $\mathrm{min}^{-1}$, blood pressure-130/80 $\mathrm{mm} \mathrm{Hg}$, and saturation-97\% were noted. The difficult airway trolley was kept ready near the operation table. Preoxygenation was

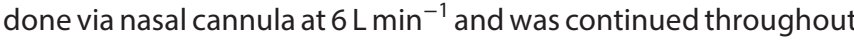
the intubation process. Conscious sedation was maintained with

(0) The Author(s). 2020 Open Access This article is distributed under the terms of the Creative Commons Attribution 4.0 International License (https://creativecommons. org/licenses/by-nc/4.0/), which permits unrestricted use, distribution, and non-commercial reproduction in any medium, provided you give appropriate credit to the original author(s) and the source, provide a link to the Creative Commons license, and indicate if changes were made. The Creative Commons Public Domain Dedication waiver (http://creativecommons.org/publicdomain/zero/1.0/) applies to the data made available in this article, unless otherwise stated. 


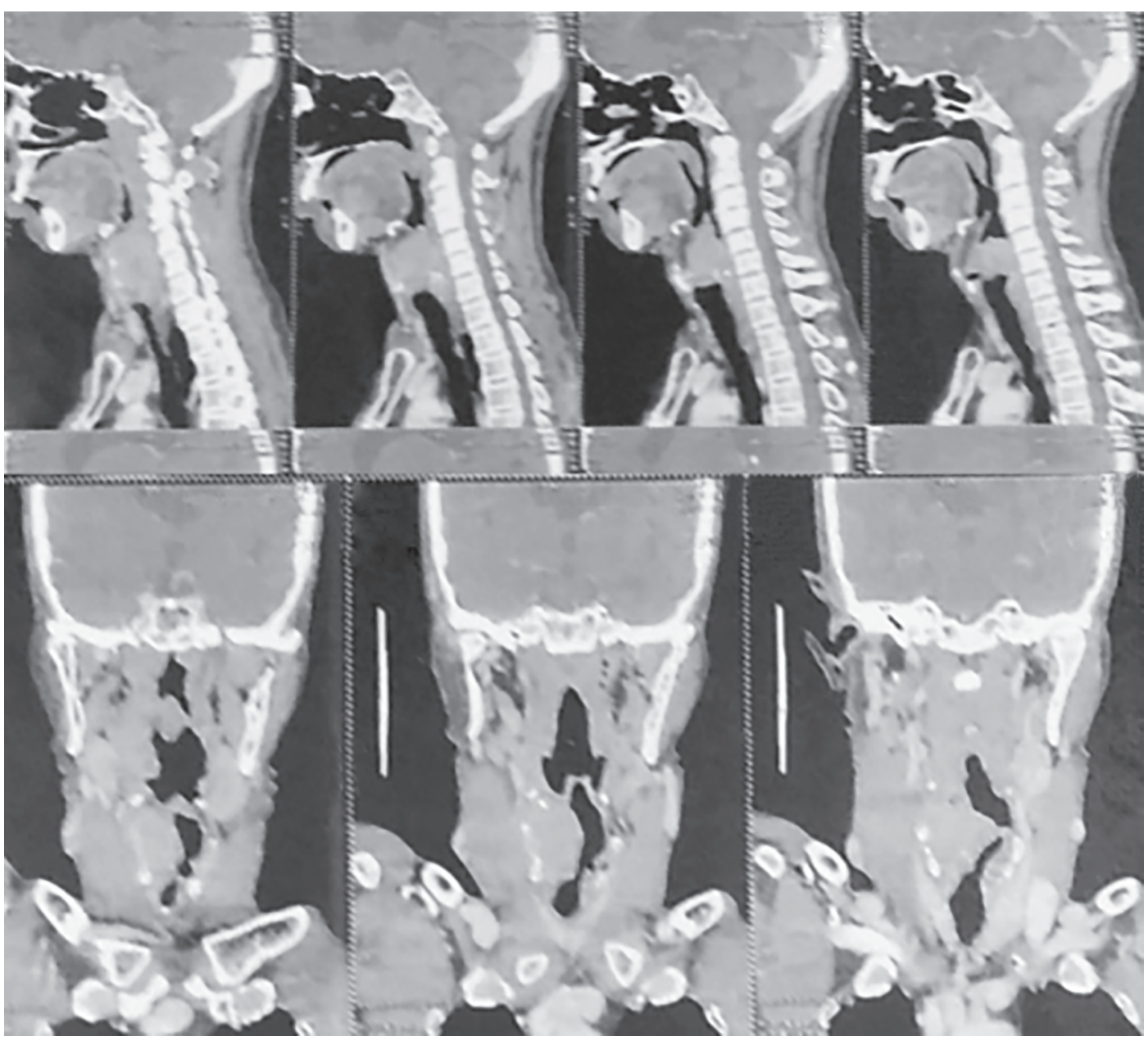

Fig. 1: Contrast-enhanced CT scan of the neck. Sagittal and coronal views of the airway, tumor obstructing the airway

dexmedetomidine infusion at $0.5 \mu \mathrm{g} \mathrm{kg}^{-1} \min ^{-1}$ for 10 minutes. ${ }^{5}$ Bilateral superior laryngeal and glossopharyngeal nerve were blocked by injecting $2 \%$ lignocaine $2 \mathrm{~mL}$ on each side to anesthetize supraglottic structures. Transtracheal injection at the cricothyroid membrane was given with $2 \mathrm{~mL}$ of $4 \%$ lignocaine to anesthetize the infraglottic structures. McGrath ${ }^{\circledast}$ Mac VL was used and the Cormack-Lehane score was $2 \mathrm{~b}$ (Fig. 2). The bougie was difficult to pass through the opening at first and needed two attempts. Advancing a larger endotracheal tube (ETT) through the bougie could damage the tumor or push the tumor particles deeper into the airway, which could cause major problems such as endobronchial occlusion. Therefore, a smaller diameter flexometallic tube (FMT) ID $6.0 \mathrm{~mm}$ was passed over the bougie. Endotracheal intubation was confirmed by capnography and auscultation. Propofol $100 \mathrm{mg}$ and vecuronium $6 \mathrm{mg}$ were given to the patient. Maintenance of anesthesia was achieved with oxygen, sevoflurane, nitrous oxide, and vecuronium was given as per the requirements for muscle relaxation. After bilateral MRND, a cuffed tracheostomy tube ID 8.0 $\mathrm{mm}$ was inserted and the oral FMT was removed. The circuit was attached to the tracheostomy tube and ventilation was confirmed. Dexamethasone $8 \mathrm{mg}$, ondansetron $4 \mathrm{mg}$, and paracetamol $1 \mathrm{~g}$ were given intravenously 1 hour before the end of the surgery. The surgery was uneventful and lasted for 6 hours. In the end, the neuromuscular blockade was reversed with neostigmine $(2.5 \mathrm{mg})$

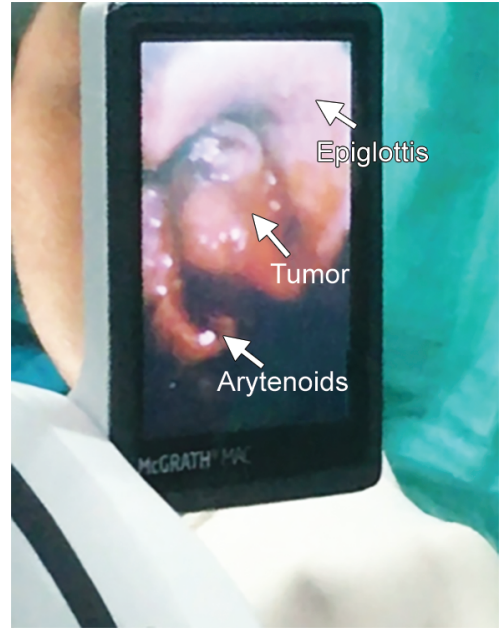

Fig. 2: Tumor obstructing the glottic opening seen on McGrath ${ }^{\circledR}$ Mac videolaryngoscope

and glycopyrrolate $(0.4 \mathrm{mg})$. The patient was shifted to the intensive care unit (ICU) on T-piece with the tracheostomy tube in situ for observation. After 48 hours postoperatively, the patient was shifted to the ward. 


\section{Discussion}

Carcinoma of the pyriform fossa is a highly malignant disease with a poor prognosis. Bilateral lymph node metastasis is common because of the rich lymphatic network. Management includes a thorough evaluation of the airway and formulations of different plans preoperatively to decrease the morbidity and mortality associated with difficult airway management. Indirect laryngoscopy should be done before the surgery to evaluate the airway including the epiglottis, glottis, the extent and form of the tumor. Discussion with the surgeon about the plan is important. Submental intubation, awake nasal intubation, and many other methods can be employed in such cases but the choice is made depending upon various patient factors as well as the availability of equipment and experience of an anesthesiologist.

Awake intubation is indicated when there is a risk of "cannot intubate cannot oxygenate". In our case, awake oral intubation with a VL was preferred due to the non-availability of FOB and to avoid a complete occlusion of glottis after induction of anesthesia which could occur due to relaxation of pharyngeal and laryngeal muscles that maintain the patency of the airway during awake spontaneous breathing. ${ }^{6}$

Fiberoptic intubation is the gold standard but its availability and the expertise in its use are two big limitations. The part of the device must pass through a limited glottic space without causing major patient discomfort. Shamim et al. successfully managed the airway using awake VL in rare thyroid cancer with grade III goiter and intratracheal invasion when the fiberoptic intubation failed. ${ }^{7}$ Moore and Schricker have shown in their meta-analysis that VL provides similar success rates and faster intubation times when compared with FOB intubation in awake patients with difficult airways. ${ }^{3}$

Awake intubation using a McGrath ${ }^{\oplus}$ Mac VL has several benefits over fiberoptic bronchoscopy. The device does not have to pass through the narrow glottic opening, reducing the chances of the tumor getting damaged or pushed into the airway by the tube. ${ }^{2}$ More importantly, the laryngoscopic view provides full visualization of the ETT tip for more controlled and safer advancement into the glottic aperture. Moreover, the airway preparation helped us for smooth intubation and provided patient comfort.

\section{Conclusion}

As described in the present case, awake intubation using a McGrath ${ }^{\circledR}$ $\mathrm{VL}$ is a good alternative to awake intubation with FOB for difficult airway management as it significantly improves the laryngeal exposure and can facilitate safe intubation through narrowed vocal cords. However, the device alone will not lead to success in all clinical cases. Equipment and the drugs for anticipated difficult airway and cardiopulmonary resuscitation should be kept available for instant application in cases of a difficult airway.

\section{References}

1. Pracy P, Loughran S, Good J, et al. Hypopharyngeal cancer: United Kingdom national multidisciplinary guidelines. J Laryngol Otol 2016;130(S2):104-110. DOI: 10.1017/S0022215116000529.

2. Min Lee S, Lim H. McGrath ${ }^{\circledast}$ videolaryngoscopy in an awake patient with a huge dangling vocal papilloma: a case report. J Int Med Res 2019;47(7):3416-3420. DOI: 10.1177/0300060519851355.

3. Moore A, Schricker T. Awake videolaryngoscopy versus fiberoptic bronchoscopy. Curr Opin Anaesthesiol 2019;32(6):764-768. DOI: 10.1097/ACO.0000000000000771.

4. Chapane S, Salgaonkar S, Tadvi S. Ventilating bougie guided flexometalic tube intubation with airtraq-not a technique of choice? J Anaesth Crit Care Case Rep 2017;3(1):22-24.

5. Sharma J, Purohit S, Bhatia S, et al. Awake orotracheal fibre-optic intubation: Comparison of two different doses of dexmedetomidine on intubation conditions in patients undergoing cervical spine surgery. Indian J Anaesth 2017;61(10):811-817. DOI: 10.4103/ija. IJA_169_17.

6. Bajwa SJ. Management of difficult airway during laryngectomy and thyroidectomy. Med J DY Patil Univ 2014;7(3):342. DOI: 10.4103/09752870.128978.

7. Shamim F, Jangda I, Ikram M. Successful airway management using awake videolaryngoscopy for a rare thyroid cancer with grade iii goitre and intra-tracheal invasion. Turk J Anaesthesiol Reanim 2020;48:156-159. DOI: 10.5152/TJAR.2019.13333. 